\title{
Effect of Borax Pentahydrate Addition to Acid Bath on the Microstructure and Corrosion Resistance of Zn-Co Coating
}

\author{
İ.H. KARAHAN* \\ Mustafa Kemal University, Faculty of Art and Science, Department of Physics, Hatay, Turkey
}

\begin{abstract}
In this work, the Zn-Co coatings were synthesized on AISI 4140 steel and aluminum plates by using potentiostatic electrodeposition technique in sulphate-based acidic baths with $0,20,40$ and $60 \mathrm{gl}^{-1}$ of borax pentahydrate, as additive. The effect of borax pentahydrate on the microstructure of the samples was observed using scanning electron microscopy and X-ray diffractometer. The deposition process was investigated by cyclic voltammetry. The effect of borax pentahydrate on the corrosion resistance of the samples was studied by potentiodynamic polarization technique. The results have demonstrated, that the addition of borax pentahydrate was in favor of the growth of grains. The morphology of pyramidal islands on the surface was changed to a more flat structure. The results have also demonstrated that the effect of borax pentahydrate was not monotonous. With increasing concentration, the corrosion potential was at minimum and the charge transfer resistance $R_{\mathrm{t}}$ was at maximum for the sample obtained from the bath with $60 \mathrm{gl}^{-1}$ of borax pentahydate, indicating that this sample showed the best corrosion resistance. It was found that current density first decreased and than increased, due to adsorption of a complex of borax pentahydrate and/or changes in the morphology, however, the initial deposition potential was not affected. The addition of borax pentahydrate to the bath led to formation of the best $\mathrm{Zn}-\mathrm{Co}$ deposits, composed of coalesced globular fine grains, smaller than $\approx 2 \mu \mathrm{m}$ in diameter. In addition, all of the studied $\mathrm{Zn}-\mathrm{Co}$ deposits consisted of $\eta$ phases. It is suggested that $\mathrm{Zn}-\mathrm{Co}$ deposits produced in the bath containing $60 \mathrm{gl}^{-1} \mathrm{of}^{-}$ borax pentahydrate probably offer sacrificial protection to the steel substrate.
\end{abstract}

DOI: 10.12693/APhysPolA.128.B-432

PACS: 68.37.-d, 68.55.-a, 81.65.Kn

\section{Introduction}

For many years, zinc has been the most widely used sacrificial coating for steel and other ferrous materials, because of its ability to provide efficient and reliable corrosion protection at a low cost [1]. There are a lot of studies to improve the durability of zinc coatings. Some indepth studies have revealed, that alloying with elements of the group-eight elements (i.e. $\mathrm{Fe}, \mathrm{Ni}, \mathrm{Co}$ ) can improve the corrosion performance of electrodeposited zinc significantly $[2-4]$. These studies are offering an important alternative to toxic cadmium coatings. Various $\mathrm{Zn}$ and iron-group-based alloys ( $\mathrm{Zn}-\mathrm{Ni}, \mathrm{Zn}-\mathrm{Co}$ and $\mathrm{Zn}-\mathrm{Fe}$ ) are currently used in industry. Such zinc alloy coatings possess higher corrosion resistance than the pure zinc coatings $[1,4,5]$. The electrodeposition of these $\mathrm{Zn}$ alloys is considered as codeposition of the anomalous type, according to the Brenner definition, and the nature of the electrodeposition results sometimes in unidentified phase structures, i.e. different from the equilibrium phases [4]. Therefore, the cobalt content in the $\mathrm{Zn}-\mathrm{Co}$ alloys, produced from aqueous coating baths, is still at low rates. In spite of the fact that there are numerous publications regarding $\mathrm{Zn}-\mathrm{Co}$ alloy with low Co content [6-11], there has not been much work reported on $\mathrm{Zn}-\mathrm{Co}$ alloys consisting of considerably higher Co contents. Most results reported on the electrodeposition of $\mathrm{Zn}-\mathrm{Co}$ alloy coatings showed that the maximum amount of cobalt

\footnotetext{
*e-mail: ikarahan@mku.edu.tr
}

in their deposits was about $6-7$ wt. $\%[12,13]$. The deposits of $\mathrm{Zn}-\mathrm{Co}$ alloys with cobalt content of more than 6 or 7 wt.\% have not been widely reported $[14,15]$. Fei et al. [16] have obtained $\mathrm{Zn}-\mathrm{Co}$ alloy deposits in the wide cobalt content range of $10-90 \%$.

The use of additives in electrolytic bath is very crucial, owing to their influence on the growth and structure of the deposits obtained [17-20]. Adding small amounts of an additive in electrolytic bath improves smoothness and luster of the deposits. Their effect on electroplating is generally known to be due to adsorbtion on the cathode surface and alteration of the activation energy [21] and the rate of charge transfer in the electrochemical reaction, and also due to alteration of the electrocrystallization process $[22,23]$.

In our previous study, investigating the relation between the corrosion properties and addition of gelatin in $\mathrm{Zn}-\mathrm{Fe}$ alloys [24], the results indicated a strong evidence of an increase in corrosion potential with the addition of gelatin to the electrolyte. Mouanga, et al. [19] have studied the influence of coumarin on $\mathrm{Zn}-\mathrm{Co}$ alloy, obtained from a sulphate bath. They have found that wellstructured $\mathrm{Zn}-\mathrm{Co}$ alloys, with a finer grain size, were obtained in the presence of coumarin and that this additive affects the reduction of zinc, but it has no effect on the reduction of cobalt. They have also noticed, that the presence of coumarin in the electrolyte resulted in structural refinement of alloy deposits and increase of cathodic current efficiency. Barbosa and Carlos [25] have used sorbitol for electrodeposition of $\mathrm{Zn}-\mathrm{Fe}$ as a complexing agent in alkaline bath. They observed, that it is useful for minimizing the potential difference between iron and 
zinc. $\mathrm{Wu}$, et al. have introduced borax pentahydrate into an ammonia-citric plating bath of $\mathrm{Ni}-\mathrm{W}$ alloys. They have found that borax pentahydrate acted as a surfactant to impede the proton reduction [26]. Gharahcheshmeh, et al. have studied $\mathrm{Zn}-\mathrm{Co}$ deposition from an alkaline bath in the presence of glycine. They have shown, that cobalt was deposited at a potential near to that of zinc, and have achieved successful co-deposition of Co and Zn. They have also shown that reduction-oxidation (redox) reactions of $\mathrm{Zn}-\mathrm{Co}$ alloy deposits are quasi-reversible and result in deviation of electrodeposited alloys from the equilibrium phase diagrams. The corrosion resistance of the deposits was also highly influenced by the composition and morphology of the coatings [27]. In another study, we have investigated the electrodeposition of $\mathrm{Zn}$-Co alloys from a cyanide free alkaline bath in the presence of boric acid as a complexing agent and we found that increasing boric acid content caused an increase in cobalt content in the film. An increase of boric acid content in the electrolyte up to $60 \mathrm{gl}^{-1}$ led to the formation of the best $\mathrm{Zn}$-Co deposits, composed of coalesced globular fine grains, smaller than $\approx 2 \mu \mathrm{m}$ in diameter and, thereby, Zn-Co alloys have presented a lower degree of corrosion [28].

In this study, electrodeposition of $\mathrm{Zn}$-Co alloys from a cyanide free alkaline bath in the presence of borax pentahydrate, as a complexing agent, was investigated using potentiostatic deposition method. Cyclic voltammetry was also used to study co-deposition of zinc and cobalt. Scanning electron microscopy (SEM) and X-ray diffraction (XRD) analyses of $\mathrm{Zn}-\mathrm{Co}$ films were applied to determine the morphology, composition, and structure of the coatings, respectively. Finally, the corrosive properties of electrodeposited Zn-Co alloy coatings were investigated as a function of borax pentahydrate content in the electrolyte.

\section{Experimental}

$\mathrm{Zn}_{1-x} \mathrm{Co}_{x}$ alloys were prepared by electrodeposition under potentiostatic conditions on aluminum and AISI 4140 steel disk substrates from a sulphate plating bath at room temperature (Table). The electrolytes were prepared using $(18 \mathrm{M} \Omega \mathrm{cm})$ twice distilled water. The dimensions of the deposits were about $1.5 \times 1.5 \mathrm{~cm}^{2}$. Before the deposition, the substrates are prepared in the standard industrial way and then dried in air. Thus, the wettability and therefore the reactivity of the substrate surface were increased. After these preparation steps, the substrates were ready to be electrodeposited. Platinum electrode was used as a counter electrode. The reference electrode used in all experiments was a saturated calomel electrode (SCE).

The surface structure of the electrodeposits was examined using JEOL 6400 scanning electron microscope (SEM) working at $15-30 \mathrm{kV}$. The preferred orientations of the deposits were determined by X-ray diffraction (XRD) analysis, using a Siemens D500 X-ray diffractometer with $\mathrm{Cu} \mathrm{K} \mathrm{K}_{\alpha}$ radiation. The $2 \theta$ range of $0-90^{\circ}$ was
TABLE

Solution compositions for the $\mathrm{Zn}-\mathrm{Co}$ alloy electrodeposition.

\begin{tabular}{|c|c|}
\hline Solution compositions & $\mathrm{ZnCo}$ \\
\hline $\mathrm{ZnSO}_{4}[\mathrm{M}]$ & 0.5 \\
\hline $\mathrm{CoSO}_{4}[\mathrm{M}]$ & 0.1 \\
\hline $\mathrm{C}_{6} \mathrm{H}_{5} \mathrm{Na}_{3} \mathrm{O}_{7} \cdot 2 \mathrm{H}_{2} \mathrm{O}\left[\mathrm{g} \mathrm{l}^{-1}\right]$ & 25 \\
\hline Borax $\left[\mathrm{gl}^{-1}\right]$ & $0-20-40-60-80$ \\
\hline $\mathrm{NH}_{4} \mathrm{Cl}\left[\mathrm{g} \mathrm{l}^{-1}\right]$ & 45 \\
\hline $\mathrm{Na}_{2} \mathrm{SO}_{4}\left[\mathrm{~g} \mathrm{l}^{-1}\right]$ & 0.5 \\
\hline Solution $\mathrm{pH}$ & 5 \\
\hline Temperature $\left[{ }^{\circ} \mathrm{C}\right]$ & Room temperature \\
\hline Deposition time [min] & 10 \\
\hline Voltage [V] & -3 \\
\hline
\end{tabular}

recorded at a rate of $0.02^{\circ} 2 \theta / 0.5 \mathrm{~s}$. The crystal phases were identified by comparing the $2 \theta$ values and intensities. The thickness of the deposits was determined by an $\mathrm{X}$-Ray fluorescence spectrometer as $\approx 2 \mu \mathrm{m}$.

The electrochemical behaviour of the electrodeposited $\mathrm{Zn}-\mathrm{Co}$ alloys was analysed in $5 \mathrm{wt} . \% \mathrm{NaCl}$ aqueous solution at room temperature in a Pyrex glass cell. The corrosion behaviour of the samples was investigated by a potentiodynamic polarization technique. Polarization measurements were performed with an electrochemical analyser/workstation (Model 1100, CH Instruments, USA) with a three-electrode configuration. The exposed areas of the specimens were about $1 \mathrm{~cm}^{2}$. The specimens were embedded in a cold setting resin and immersed into the solution until a steady open circuit potential (ocp) was reached. After equilibration (45 min later), polarization was started at a rate of $1 \mathrm{mV} / \mathrm{s}$.

\section{Results and discussion}

To determine the main characteristics of the zinc, cobalt and $\mathrm{Zn}-\mathrm{Co}$ alloy deposition process, the cyclic voltammetry technique was used. Figure 1 shows voltammetric diagrams of $\mathrm{Zn}$-Co deposition from coating baths, containing various amounts of borax pentahydrate. The scans were performed near open circuit potentials of the baths.

In solutions, during the forward scan towards the negative direction, as it can be seen, there is a sharp increase of the cathodic current when the deposition starts. Without borax, the deposition started at $-1.18 \mathrm{~V}$ because of the dominancy of the $\mathrm{Zn}$ deposition. In the anodic scan the broad peak at about $-0.6 \mathrm{~V}$ can be attributed to dissolution of pure Zn and/or Zn from the $\eta$ phase (a solid solution of Co in Zn with a hcp structure), and the peak at $-0.35 \mathrm{~V}$ can be attributed to dissolution of Co [29]. In the presence of borax pentahydrate, dissolution peak of Co cannot be seen. This can be related to the effect of inhibition by borax of the oxidation of the deposits. The presence of borax has increased the intensity of the Zn dissolution peak; it shows that, adding borax causes a higher content of Zn-rich phases in the coating alloy. 


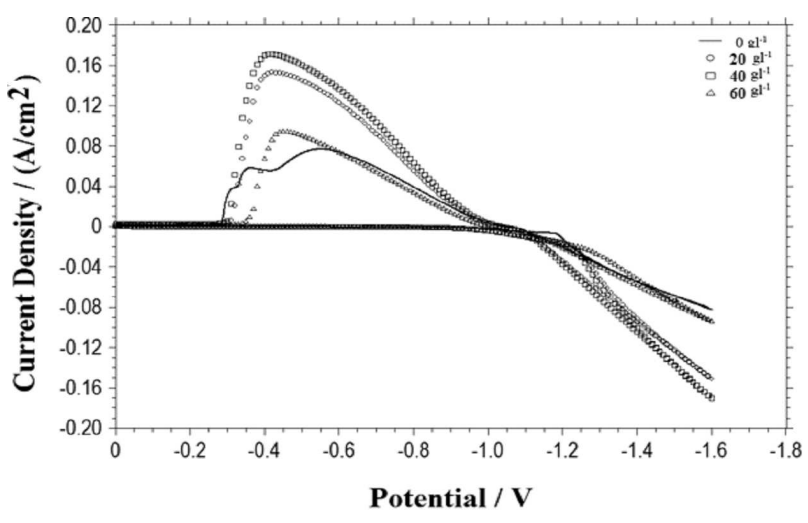

Fig. 1. Cyclic voltammograms for different borax pentahydrate content values.

As it can be seen, adding ever-increasing amounts of borax, firstly causes an increase and then a decrease in current density and a dissolution peak.

Figure 2 shows the XRD patterns of the electrodeposited $\mathrm{Zn}_{1-x} \mathrm{Co}_{x}$ alloys, from electrolytic baths containing different amounts of borax pentahydrate, varied between 0 and $60 \mathrm{gl}^{-1}$. The XRD analysis showed that electrodeposited samples have polycrystalline structure.

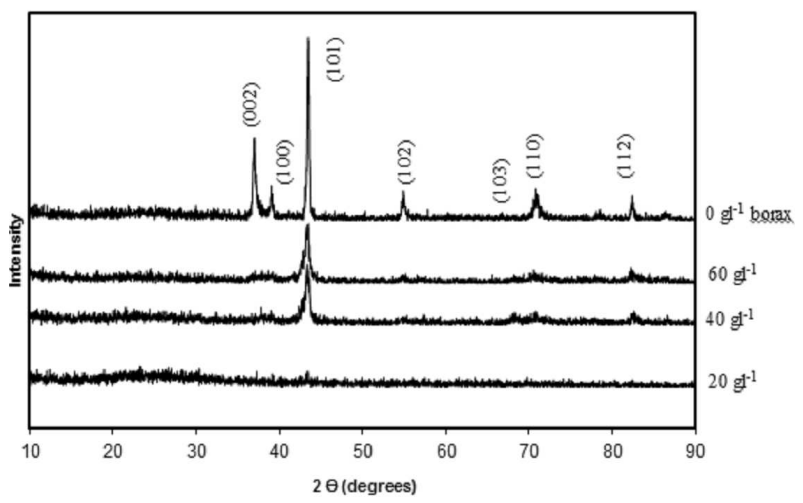

Fig. 2. XRD pattern of $\mathrm{Zn}-\mathrm{Co}$ coating obtained in electrolyte containing: $0,20,40,60 \mathrm{~g} \mathrm{l}^{-1}$ of borax.

The X-ray diffraction patterns of the deposits, whether from the solution with borax or not, exhibit a preferred orientation along the (002), (100), (101), (102), (103), (110) and (112) planes. The preferred crystal orientation of zinc electrodeposits depends on the experimental conditions $[11,30]$ such as current density, $\mathrm{pH}$, and temperature. Peaks originating from (002), (100), (101), (102), (103) and (112) planes can be seen clearly in the absence of the borax. XRD pattern of the sample which is obtained from the bath containing $20 \mathrm{gl}^{-1}$ of borax has been flattened because of increasing amounts of amorphous components in the coating. Samples which are obtained from the baths with $40 \mathrm{~g} \mathrm{l}^{-1}$ and $60 \mathrm{~g} \mathrm{l}^{-1}$ of borax have similar patterns, including all the peaks (with relatively lower intensities) seen in the absence of borax.
We can easily assert, that presence of borax has clearly hindered the formation of all planes except (101). Presence of borax has hindered the formation of (101) also in the coating bath containing $20 \mathrm{~g} \mathrm{l}^{-1}$ of borax.

The surface morphology of the electrodeposited ZnCo alloys was investigated by SEM. The effect of the borax content in electrolytic bath on surface morphology of the electrodeposited Zn-Co alloys can be seen in Fig. 3. The film obtained from the bath containing $20 \mathrm{gl}^{-1}$ of borax (Fig. 3a) has typical appearance of $\mathrm{Zn}$ crystallization. Small uniform grains have been crystallized and grew by showing the nucleation. No gaps have been seen, although the formation of interstices between the nodules was observed. Whereas in the films obtained from the bath containing $40 \mathrm{gl}^{-1}$ (Fig. 3b) and $60 \mathrm{~g} \mathrm{l}^{-1}$ of borax (Fig. 3c), nucleation has disappeared, although in some places of the film obtained with $60 \mathrm{~g} \mathrm{l}^{-1}$ of borax the nucleation can be seen. Gaps and clusters have emerged. The morphology of pyramidal islands on the surface has changed to a more flat structure. We can suggest that borax has inhibitive effect on nucleation.

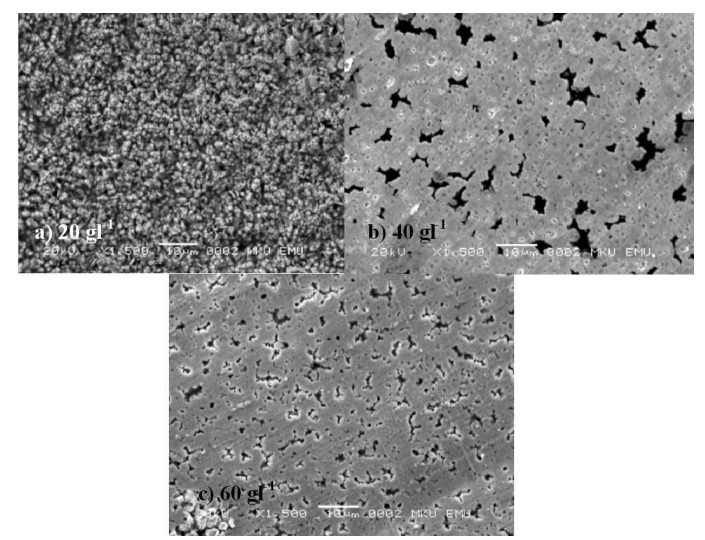

Fig. 3. SEM images of the $\mathrm{Zn}-\mathrm{Co}$ films electrodeposited at different borax pentahydrate contents in the electrolyte: (a) $20 \mathrm{gl}^{-1}$, (b) $40 \mathrm{gl}^{-1}$ and (c) $60 \mathrm{gl}^{-1}$ of borax pentahydrate.

Figure 4 shows the influence of addition of 20, 40 and $60 \mathrm{gl}^{-1}$ of borax on the corrosion-resistance property of electrodeposited Zn-Co alloy, obtained in a sulfate bath, in a 3 wt.\% $\mathrm{NaCl}$ aqueous solution. Two stages of passivation are observed in $\mathrm{Zn}-\mathrm{Co}$ alloy coatings. This can be an indication of two stages in the formation of protective film. When $\mathrm{Zn}-\mathrm{Co}$ alloy is corroded, zinc begins to dissolve preferentially according to Eqs. (1)-(4) [10, 17].

$$
\begin{aligned}
& \mathrm{Zn}(s) \rightarrow \mathrm{Zn}^{2+}(\mathrm{aq})+2 e^{-}, \\
& \mathrm{O}_{2}(g)+2 \mathrm{H}_{2} \mathrm{O}(l)+4 e^{-} \rightarrow 4 \mathrm{OH}^{-}(\mathrm{aq}), \\
& \mathrm{Zn}^{2+}(\mathrm{aq})+2 \mathrm{OH}^{-}(\mathrm{aq}) \rightarrow \mathrm{Zn}(\mathrm{OH})_{2}(s), \\
& \mathrm{Zn}(\mathrm{OH})_{2}(s) \rightarrow \mathrm{ZnO}(s)+\mathrm{H}_{2} \mathrm{O} .
\end{aligned}
$$

Therefore, the protective films are complex compositions including $\mathrm{Zn}(\mathrm{OH})_{2}$ and $\mathrm{ZnO}$, that cover the surfaces of the corroded coatings and create areas in which current density is independent of potential. 


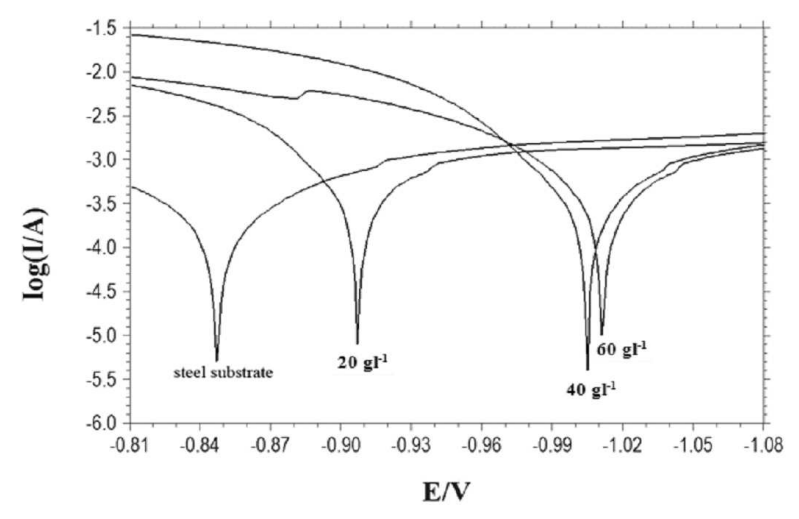

Fig. 4. Influence of borax pentahydrate concentration on corrosion properties of $\mathrm{Zn}$-Co:AISI 4140 steel in a 5 wt.\% $\mathrm{NaCl}$ aqueous solution.

The presence of cobalt in the coating enhances dissolution of zinc in $\mathrm{NaCl}$ solution. Consequently, the increase in zinc dissolution causes its reaction with chloride ions in $\mathrm{NaCl}$ solution and formation of zinc hydroxy chloride, according to Eq. (5) [7, 17].

$5 \mathrm{Zn}^{2+}+8 \mathrm{OH}^{-}+2 \mathrm{Cl}^{-}+\mathrm{H}_{2} \mathrm{O} \rightarrow \mathrm{Zn}_{5} \mathrm{OH}_{8} \mathrm{Cl}_{2} \mathrm{H}_{2} \mathrm{O} .(5)$ Zinc hydroxy chloride has a very low solubility, and ensures higher protective ability for $\mathrm{Zn}-\mathrm{Co}$ alloy coatings $[7,10]$.

We can easily conclude that the film obtained from bath containing $20 \mathrm{gl}^{-1}$ of borax has the highest corrosion resistance among studied films. An increase of borax content in electrolytic bath has led to a shift of corrosion potential to more negative values.

\section{Conclusion}

Compact and bright Zn-Co binary alloys were electroplated satisfactorily on steel sheet from baths containing cobalt sulfate, copper sulfate, sodium sulfate, sodium citrate and borax pentahydrate $(\mathrm{pH}=5)$. The effects of borax pentahydrate concentration on cathodic polarization, crystal and surface structure of the deposited alloys were investigated. The deposited alloys consisted of a single solid solution phase with a hexagonal structure, irrespective of the borax pentahydrate content in the electrolytic bath. These alloys can be used for sacrificial purposes, and to protect steels from corrosion, because of their relatively high passivation effect.

\section{References}

[1] Metals Handbook, vol. 5, American Society of Metals, Metals Park 1982, p. 244.

[2] G.D. Wilcox, D.R. Gabe, Corros. Sci. 35, 1251 (1993).

[3] D.R. Gabe, Electrochim. Acta 39, 1115 (1994).

[4] A. Brenner, Electrodeposition of Alloys, Principle and Practice, Academic Press, New York 1963, p. 152.
[5] I.H. Karahan, A. Tozar, Appl. Surf. Sci. 318, 100 (2014).

[6] P.Y. Chen, I.W. Sun, Electrochim. Acta 46, 1169 (2001).

[7] N. Boshkov, K. Petrov, D. Kovacheva, S. Vitkova, S. Nemska, Electrochim. Acta 51, 77 (2005).

[8] R. Ramanauskas, L. Muleshkova, L. Maldonado, P. Dobrovolskis, Corros. Sci. 40, 401 (1998).

[9] R. Ramanauskas, R. Juskenas, A. Kalinicenko, L.F. Darfias-Mesias, J. Solid State Electrochem. 8, 416 (2004).

[10] N. Boshkov, K. Petrov, S. Vitkova, S. Nemska, G. Raichevsky, Surf. Coat. Technol. 157, 171 (2002).

[11] J.B. Bajat, V.B. Mišković-Stanković, M.D. Maksimović, D.M. Dražić, S. Zec, Electrochim. Acta 47, 4101 (2002).

[12] H. Yan, J. Downes, P.S. Boden, S.J. Harris, J. Electrochem. Soc. 143, 1577 (1996).

[13] I. Kirilova, I. Ivanov, J. Appl. Electrochem. 29, 1133 (1999).

[14] N.R. Short, A. Abibsi, J.K. Dennis, Trans. Inst. Met. Finish. 67, 73 (1989).

[15] M.E. Bahrololoom, D.R. Gabe, G.D. Wilcox, J. Electrochem. Soc. 150, C144 (2003).

[16] J-Y. Fei, G.D. Wilcox, Electrochim. Acta 50, 2693 (2005).

[17] P.D.L. Neto, A.N. Correia, R.P. Colares, W.S. Araujo, J. Braz. Chem. Soc. 18, 1164 (2007).

[18] M. Mouanga, L. Ricq, L. Ismaili, B. Refouvelet, P. Bercot, Surf. Coat. Technol. 201, 7143 (2007).

[19] M. Mouanga, L. Ricq, P. Bercot, Surf. Coat. Technol. 202, 1645 (2008).

[20] M. Mouanga, L. Ricq, G. Douglade, J. Douglade, P. Bercot, Surf. Coat. Technol. 201, 762 (2006).

[21] D.J. MacKinnon, J.M. Brannen, J. Appl. Electrochem. 12, 21 (1982).

[22] E. Michailova, M. Peykova, D. Stoychev, A. Milchev, J. Electroanal. Chem. 366, 195 (1994).

[23] J.C. Ballesteros, P. Diaz-Arista, Y. Meas, R. Ortega, G. Trejo, Electrochim. Acta 52, 3686 (2007).

[24] İ.H. Karahan, H.A. Çetinkara, H.S. Güder, Trans. Inst. Met. Finish. 86, 157 (2008).

[25] L.L. Barbosa, I.A. Carlos, Surf. Coat. Technol. 201, 1695 (2006).

[26] Y. Wu, D. Chang, D. Kim, S-C. Kwon, Surf. Coat. Tech. 173259 (2003).

[27] M.H. Gharahcheshmeh, M.H. Sohi, J. Appl. Electrochem. 40, 1563 (2010).

[28] İ.H. Karahan, H.A. Cetinkara, Trans. Inst. Met. Finish 89, 99 (2011).

[29] E. Gómez, X. Alcobe, E. Vallés, J. Electroanal. Chem. 505, 54 (2001).

[30] Y. Oren, U. Landau, Electrochim. Acta 27, 739 (1982). 